\title{
Initiation of insulin therapy in elderly patients taking oral antidiabetes drugs
}

\author{
Norma Pérez BPharm MSc, Jocelyne Moisan PhD, Caroline Sirois BPharm MSc, \\ Paul Poirier MD PhD, Jean-Pierre Grégoire PhD MPH
}

$\infty$ See related commentary by Pogach, page 1287

\section{ABSTRACT}

Background: We sought to estimate the rate of initiation of insulin therapy among elderly patients using oral antidiabetes drugs and to identify the factors associated with this initiation.

Methods: We conducted a population-based cohort study involving people aged 66 or more years who were newly dispensed an oral antidiabetes drug. Individuals who had received acarbose or a thiazolidinedione were excluded. The rate of insulin initiation was calculated by use of the KaplanMeier method. Factors associated with insulin initiation were identified by multivariable Cox regression analyses.

Results: In this cohort of 69674 new users of oral antidiabetes drugs, insulin was initiated at rate of 9.7 cases per 1000 patient-years. Patients who had initially received an insulin secretagogue (rather than metformin), who were prescribed an oral antidiabetes drug by an endocrinologist or an internist, who received higher initial doses of an oral antidiabetes drug, who received oral corticosteroids, used glucometer strips, or were admitted to hospital in the year before initiation of oral antidiabetes therapy, or who received 16 or more medications were more likely than those without these characteristics to have insulin therapy initiated. In contrast, patients who received thiazides or who used up to 12 medications ( $v$. none) were less likely to have insulin therapy initiated.

Interpretation: Several factors related to drugs and health services are associated with the initiation of insulin therapy in elderly patients receiving oral antidiabetes drugs. It is unclear whether these factors predict secondary failure of oral antidiabetes drugs or instead reflect better management of type 2 diabetes.

Une version française de ce résumé est disponible à l'adresse www.cmaj.ca/cgi/content/full/180/13/1310/DC1

CMAJ 2009;180(13):1310-6

$\mathrm{T}$ lype 2 diabetes is a progressive disease that requires ongoing increases in doses and complexity of hypoglycemic pharmacotherapy. ${ }^{1}$ Although insulin may be the first agent prescribed to patients with type 2 diabetes who have marked hyperglycemia, oral antidiabetes drugs are usually the first pharmacologic treatment. In general, these drugs are first prescribed as monotherapy; however, combination therapy with 2 oral antidiabetes drugs with different mechanisms may also be a first-line option. ${ }^{2-4}$ Unfortunately, oral antidiabetes drugs have limited efficacy for long-term glucose lowering ${ }^{1.5}$ and, therefore, many patients may require insulin to achieve better metabolic control. ${ }^{6}$

There are several factors that may account for the need to initiate insulin therapy in patients taking oral antidiabetes drugs, including progressive $\beta$-cell failure, ${ }^{7}$ deterioration of insulin sensitivity because of glucose toxicity or the development of resistance to the oral antidiabetes drug. ${ }^{8,9}$ Disease severity, a younger age at diagnosis ${ }^{1,10}$ and poor adherence to treatment may also lead to poor metabolic control in patients with diabetes. ${ }^{11}$

Our study included an outpatient population of elderly patients, all of whom were new users of an oral antidiabetes drug. We sought to estimate the rate of initiation of insulin therapy and to identify factors associated with initiation of insulin therapy.

\section{Methods}

\section{Data sources}

Using the database of the Quebec health insurance board ( $\mathrm{La}$ Régie de l'assurance maladie du Québec) and the Quebec registry of hospital admissions (Maintenance et exploitation des données pour l'étude de la clientèle hospitalière [MedEcho]), we performed a population-based inception cohort study. The health insurance plan of Régie de l'assurance maladie du Québec covers all permanent residents of the province for both medical services and hospital admissions. Its public drug plan covers recipients of welfare, those not eligible for a private group plan for drug insurance and all people aged 65 years and over who do not live in an institution. This drug-plan database is accurate for prescription claims. ${ }^{12}$ In 2006 , a total of 3.2 million people (out of a population of 7.5 million) were beneficiaries of this drug plan.

A unique encrypted health number was used to link the databases and the registry at the patient level. The Régie de

From the Unité de recherche en santé des populations (Pérez, Moisan Sirois, Grégoire), Centre de recherche du centre hospitalier affilié universitaire de Québec; the Faculty of Pharmacy (Moisan, Sirois, Poirier, Grégoire), Université Laval, and the Quebec Heart and Lung Institute (Poirier), Hôpital Laval, Québec, Que. 
l'assurance maladie du Québec database served as the source of data for patient demographics (age, sex and region of residence), physician services (date, diagnosis and physician's specialty), prescription drugs dispensed (drug identification, dispensing date and number of days supply) and death. Hospital admission data (dates, primary diagnosis and up to $16 \mathrm{sec}-$ ondary diagnoses) were drawn from the Med-Echo database.

The Commission d'accès à l'information du Québec and the Comité d'éthique à la recherche du Centre hospitalier affilié universitaire de Québec gave approval for this study.

\section{Inclusion and exclusion criteria}

We asked the Régie de l'assurance maladie du Québec to identify all beneficiaries of the drug plan who had received at least 1 prescription of an oral antidiabetes drug between Jan. 1, 1998, and Dec. 24, 2004. We defined the index date as the date of the first claim for any oral antidiabetes drug during this period. To ensure that we included only new users of oral antidiabetes drugs, we excluded people who had received an oral antidiabetes drug in the 1-year period before the index date.

We defined elderly patients as those aged 66 or more years. We excluded patients aged less than 66 years. We excluded people who had received insulin in the 1-year period before the index date or at any time during the 7 days immediately after the index date. As well, we excluded patients who had not been eligible for the Quebec drug plan for the full 1-year period before the index date. We excluded patients who received as initial therapy acarbose, thiazolidinedione or combination therapy with metformin and insulin secreta- gogues, because there were few such patients and because the province of Quebec restricts reimbursement of thiazolidinediones to use as third-line therapy.

\section{Data collection and outcomes}

Patients were followed from the initiation of oral antidiabetes therapy to Dec. 31, 2004, initiation of insulin therapy, loss of eligibility for the drug plan or death, which ever came first. Patients were considered to have initiated insulin therapy if they had filled at least 1 prescription for insulin after the initiation of oral antidiabetes therapy. The person-months of follow-up comprised the interval between the index date and the date of the first prescription of insulin.

At the initiation of oral antidiabetes therapy, we assessed the following variables for association with initiation of insulin therapy: age, sex, dispensation of an oral antidiabetes drug, calendar year and region of residence (urban or rural). In the year before initiation of oral antidiabetes drug therapy, we assessed the association between the following factors and initiation of insulin therapy: use of drugs thought to predispose patients to dysglycemia (thiazides, $\beta$-blockers, antipsychotics, corticosteroids); use of drugs with a potential influence on blood glucose (angiotensin-converting-enzyme inhibitors, angiotensin-receptor antagonists, carvedilol); and the intensity of the oral antidiabetes drug treatment (mean initial dose as the proportion of a defined daily dose). The defined daily dose was the average maintenance dose per day for adults for a drug used for its main indication..$^{13}$ The daily dose was $2000 \mathrm{mg}$ for metformin, $1500 \mathrm{mg}$ for tolbutamide,

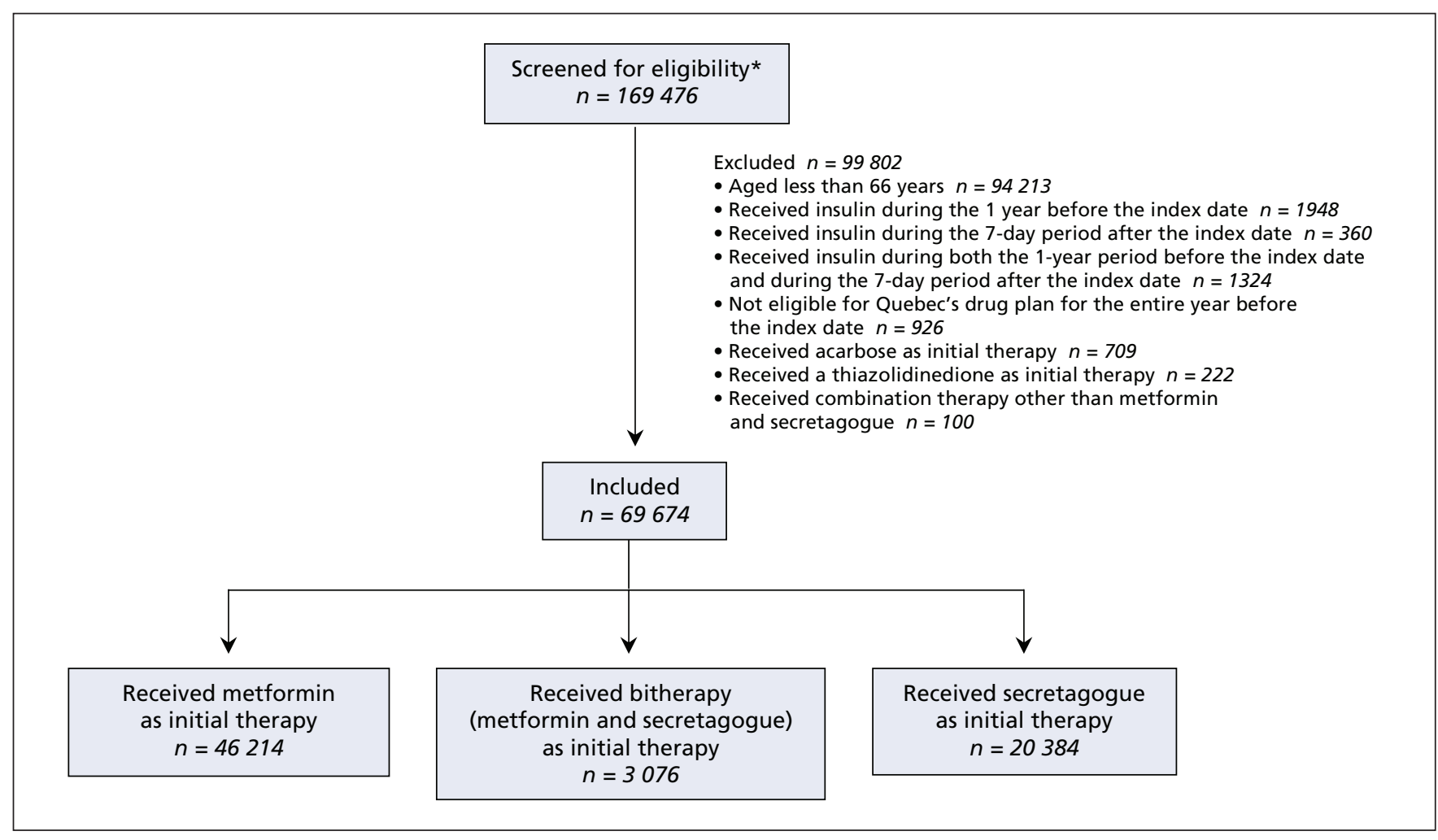

Figure 1: Selection of the study population. *Patients who received an oral antidiabetes drug between Jan. 1, 1998, and Dec. 24, 2004, and who had not taken an oral antidiabetes drug in the 1 year before the date of the first prescription. 
$375 \mathrm{mg}$ for chlropropamide, $160 \mathrm{mg}$ for glicalizide, $10 \mathrm{mg}$ for glyburide, $4 \mathrm{mg}$ for repaglinide and $2 \mathrm{mg}$ for glimepiride. We also assessed in the year before the initiation of oral antidiabetes therapy the number of different prescription drugs claimed $;{ }^{14}$ the use of glucometer strips; the number of physician visits; and the number of hospital admissions.

\section{Statistical analyses}

We calculated the incidence rate for the initiation of insulin therapy using the Kaplan-Meier method. To identify characteristics associated with the initiation of insulin therapy, we calculated hazard ratios with $99 \%$ confidence interval (CIs) using a multivariable Cox proportional-hazards model. Because we expected the analysis to be overpowered, we determined a priori a confidence interval of $99 \%$.

\section{Results}

There were a total of 69674 people included in the analysis (Figure 1). The most common initial drug therapy was metformin (66.3\% of patients), with insulin secretagogue monotherapy being less common $(29.3 \%$ ) (Table 1). The mean initial dose was equivalent to 0.5 (standard deviation 0.4 ) defined daily doses. Almost one-third of the study population was admitted to hospital at least once in the year before the index date, and about $60 \%$ of patients consulted a physician more than 10 times in that period.

In this cohort, the rate of initiation of insulin therapy was 9.7 cases per 1000 patient-years. In total, 1955 (2.8\%) patients who initially used oral antidiabetes drugs began insulin therapy during a median follow-up time of 2.9 years (Figure 2).

Of the 17 potential determinants of insulin initiation that we evaluated, 7 were statistically significant at $p<0.01$ (Table 2). Patients who received initial treatment with an insulin secretagogue (v. metformin), who had their oral antidiabetes drug prescribed by an endocrinologist or an internist (v. general practitioner), who used higher initial doses of an oral antidiabetes drug, who used oral corticosteroids, who used glucometer strips, who were admitted to hospital in the year before initiation of oral antidiabetes therapy, or who were prescribed 16 or more medications were more likely than those without these characteristics to initiate insulin therapy. Patients who received thiazides or who used up to 12 medications (v. none) had a decreased risk of insulin initiation. The

Table 1: Characteristics of elderly patients $(n=69674)$ who initiated oral antidiabetes therapy during the study period

\begin{tabular}{|c|c|c|c|}
\hline Characteristic & $\begin{array}{l}\text { No. }(\%) \\
\text { of patients }\end{array}$ & Characteristic & $\begin{array}{c}\text { No. }(\%) \\
\text { of patients }\end{array}$ \\
\hline Sex, male & $32938(47.3)$ & Angiotensin-receptor antagonist use* & 9672 (13.9) \\
\hline Residence in urban region & $55599(79.8)$ & ACE inhibitor use* & $20153(28.9)$ \\
\hline Age at oral antidiabetes drug initiation, yr & & Carvedilol use* & $200 \quad(0.3)$ \\
\hline $66-70$ & $24421(35.0)$ & Glucometer strip use* & $16096(23.1)$ \\
\hline $71-75$ & $20513(29.4)$ & No. of hospital admissions* & \\
\hline $76-80$ & 13868 (19.9) & 0 & $48812(70.1)$ \\
\hline $81-85$ & 7253 (10.4) & 1 & $12980(18.6)$ \\
\hline$\geq 86$ & $3619 \quad(5.2)$ & 2 & $4818 \quad(6.9)$ \\
\hline Initial oral antidiabetes drug & & $\geq 3$ & $3064 \quad(4.4)$ \\
\hline Metformin monotherapy & $46214(66.3)$ & No. of physician visits* & \\
\hline Secretagogue monotherapy & $20384(29.3)$ & 0 & $1261 \quad(1.8)$ \\
\hline Dual therapy (metformin and secretagogue) & $3076 \quad(4.4)$ & $1-5$ & 12931 (18.6) \\
\hline Initial prescriber's specialty & & $6-10$ & $13395(19.2)$ \\
\hline General practitioner & $59610(85.6)$ & $11-15$ & 10189 (14.6) \\
\hline Endocrinologist & $3126 \quad(4.5)$ & $16-20$ & $6980(10.0)$ \\
\hline Internist & $3719 \quad(5.3)$ & $\geq 21$ & 24918 (35.8) \\
\hline Others & $3043 \quad(4.4)$ & No. of different medications* & \\
\hline Missing & $176 \quad(0.2)$ & 0 & $4572 \quad(6.6)$ \\
\hline Thiazide use* & 17061 & $1-3$ & 12993 (18.6) \\
\hline Beta-blocker use* & $20730(29.7)$ & $4-6$ & 17150 \\
\hline Antipsychotic use* & $2418 \quad(3.5)$ & $7-9$ & $14552(20.9)$ \\
\hline Corticosteroid use* & & $10-12$ & $9386 \quad(13.5)$ \\
\hline At least 1 prescription for an oral steroid & $6657 \quad(9.5)$ & $13-15$ & 5280 \\
\hline At least 1 prescription for a non-oral steroid $t$ & $6189 \quad(8.9)$ & $\geq 16$ & $5741 \quad(8.2)$ \\
\hline
\end{tabular}

Note: $\mathrm{ACE}=$ angiotensin converting enzyme.

*Measured in the year prior to oral antidiabetes drug initiation.

tInjection or inhalation form. 
year of initiation of oral antidiabetes therapy was not associated with initiation of insulin therapy.

\section{Interpretation}

Among new elderly users of oral antidiabetes drugs, the rate of insulin initiation was 9.7 cases per 1000 patient-years. In other words, for every 1000 new users of oral antidiabetes drugs observed for 1 year, about 10 would be expected to initiate insulin therapy.

This rate of insulin initiation seems low. It is, however, difficult to interpret because it may either indicate a low rate of secondary failure of oral antidiabetes therapy in this population or that diabetes is not being treated aggressively enough. The incidence rate is helpful because it allows comparisons with different populations or in the same population over time. The incidence rate also provides the opportunity to examine factors associated with the initiation of insulin therapy.

Several of the factors that we observed to be associated with initiation of insulin therapy may reflect the effects of insulin resistance. First, in contrast with metformin, sulfonylureas do not have a stabilizing effect on weight and do not enhance insulin sensitivity. ${ }^{15}$ Second, patients receiving high initial doses of oral antidiabetes drugs are likely to have high blood glucose levels at diagnosis because of inadequate pancreatic $\beta$-cell function to keep pace with higher insulin resistance levels. These patients may require insulin earlier. Third, it is well established that corticosteroids can significantly increase glucose levels. ${ }^{16}$

Patients admitted to hospital in the year before starting an oral antidiabetes drug were more likely than those not admit- ted to be prescribed insulin. Past hospital admission may indicate patients who were more ill. Also, because the diagnosis of type 2 diabetes is often delayed, ${ }^{6,17}$ the probability of being diagnosed with type 2 diabetes might increase during a hospital stay, especially if patients have microvascular and macrovascular complications. Similarly, patients taking 16 or more drugs in the year before initiation were more likely than those taking 15 or fewer medications to be sicker, because the number of different drugs prescribed is an indicator of comorbidities. ${ }^{14}$ These patients are also more likely to consult a physician on a regular basis and, therefore, are more likely to be offered insulin. In contrast, patients who took up to 12 medications had a decreased risk compared to patients who took no medications. This result is difficult to explain.

Evidence is lacking about the relation between prior use of self-administered glycemic tests and subsequent initiation of insulin therapy. Patients who monitor their own blood glucose are used to manipulating needles and, therefore, might be less fearful of self-administering insulin injections. Also, their behaviour demonstrates that they are already taking their condition seriously. ${ }^{18}$

We found that patients taking thiazide diuretics in the year before initiation of oral antidiabetes drugs were less likely than those not taking thiazide to initiate insulin therapy. Since the early 1980s, studies of drug therapy for hypertension have documented an unfavourable effect of thiazides on plasma lipid levels. ${ }^{19}$ Thiazides are also known to induce a mild form of glucose intolerance. ${ }^{20}$ Although the development of clinically important diabetes may be unusual, it is clear that some degree of insulin resistance may be seen in many patients receiving thiazides. However, this effect is mainly seen at high

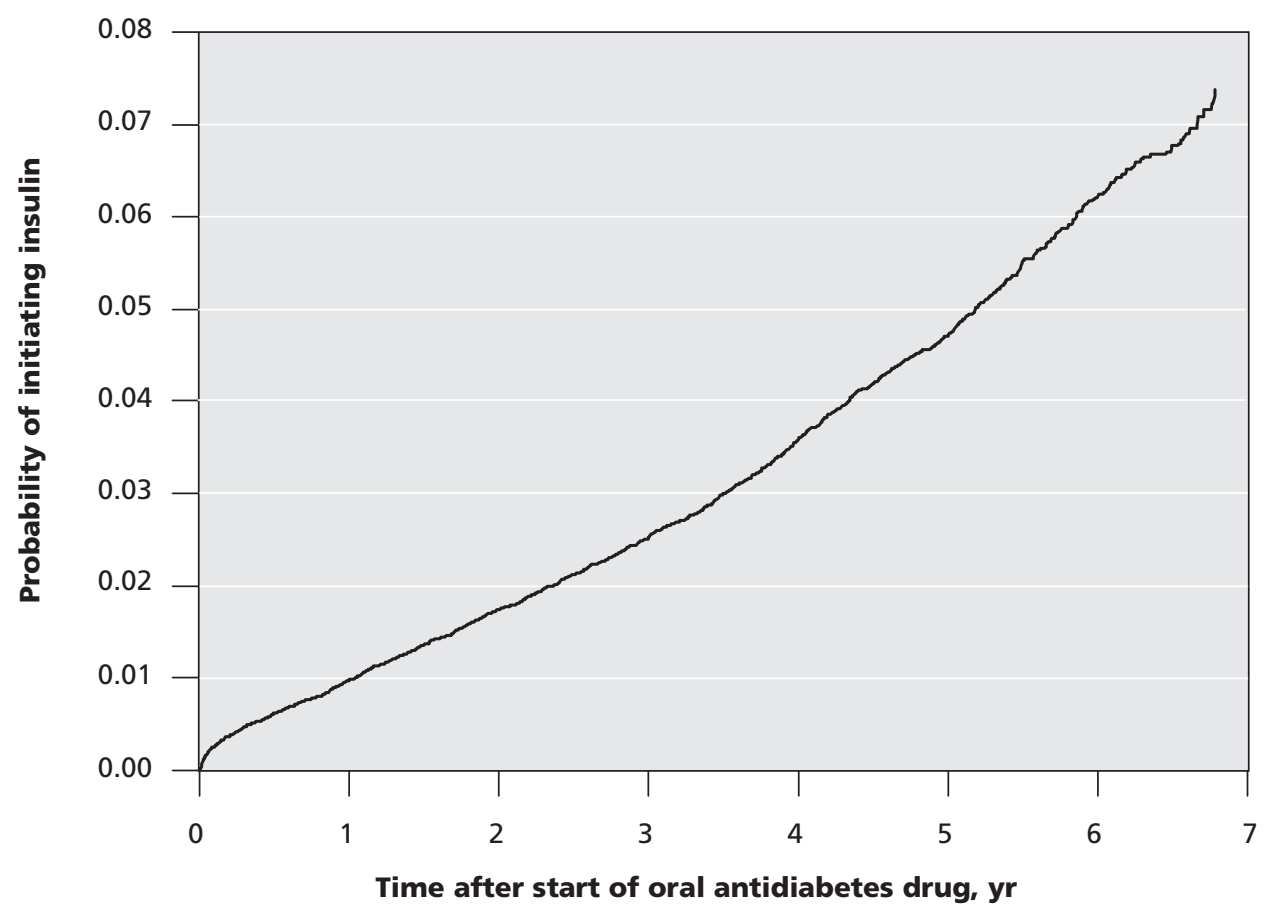

Figure 2: Initiation of insulin among patients who started to take an oral antidiabetes drug during the study period. 
doses. ${ }^{21}$ Because lower doses of thiazide, which may be metabolically neutral, are currently used,,$^{22,23}$ we no longer expect thiazides to predispose patients to dysglycemia.

Other researchers have examined the factors associated with insulin initiation among new users of oral antidiabetes drugs. A younger age, ${ }^{7}$ a low body mass index, ${ }^{7}$ being a woman, ${ }^{24}$ taking more than 1 oral antidiabetes drug, ${ }^{24}$ an in- crease in daily dosage frequency or in the number of comedications ${ }^{24}$ and having a history of myocardial infarction, dyslipidemia, depression and atrial fibrillation ${ }^{25}$ have all been reported to be predictors of insulin initiation. Researchers in these studies ${ }^{7,24,25}$ did not observe factors similar to those that we have identified. These discrepencies may be explained by differences in methodology. First, except for age and sex, the

Table 2: Factors associated with the initiation of insulin therapy in elderly patients $(n=69674)$ who initiated oral antidiabetes therapy during the study period

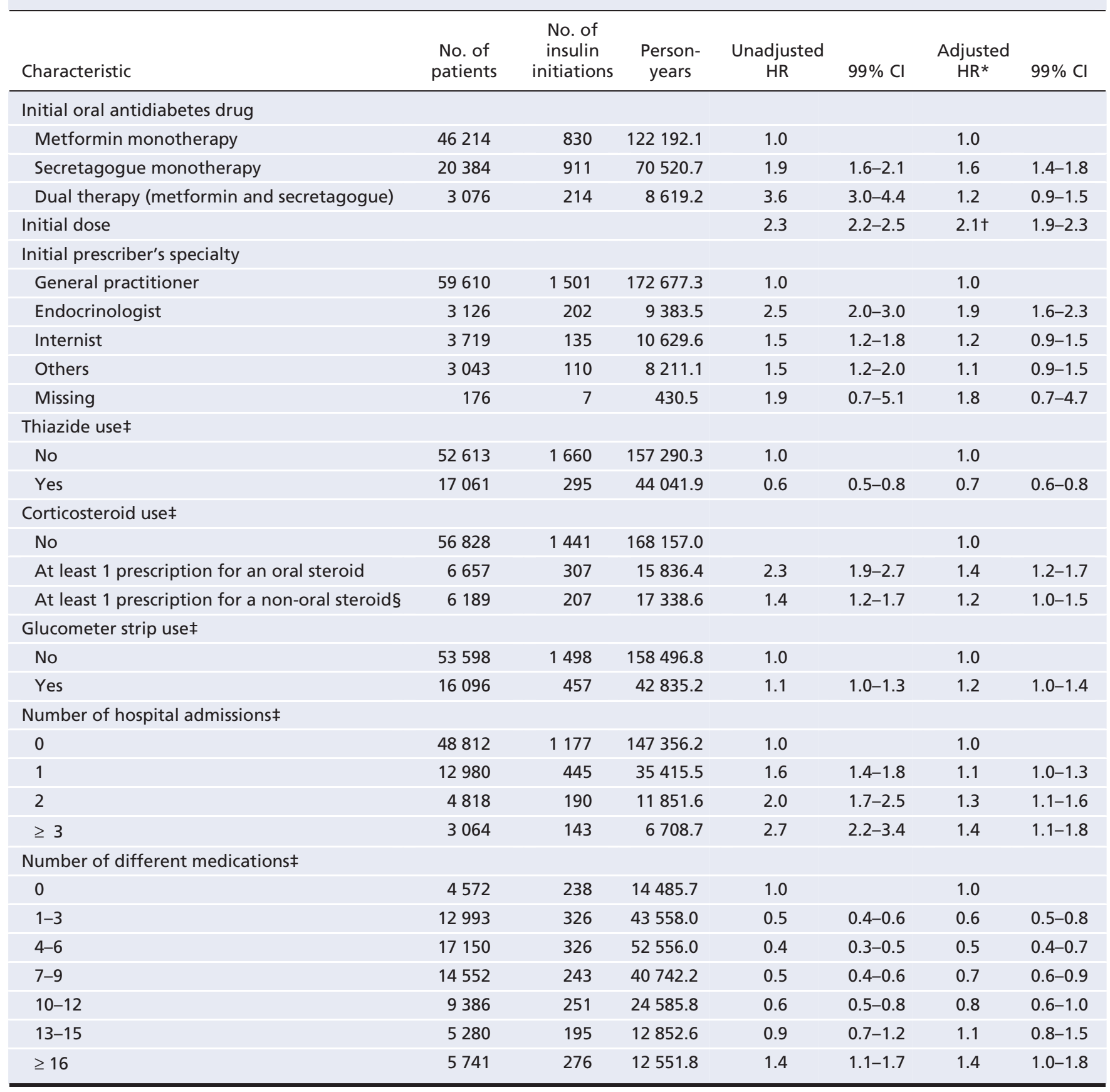

Note: $\mathrm{Cl}=$ confidence interval, $\mathrm{HR}$ = hazard ratio.

*Adjusted for all characteristics listed in Table 2 and for sex and age at treatment initiation.

tHazard ratio per 1-unit increase in initial daily dose.

$\neq$ Measured in the year prior to the initiation of oral antidiabetes drugs.

§lnjection or inhalation form. 
variables that we tested were different from those evaluated in these 3 studies. ${ }^{7,24,25}$ Second, our study population, on average, was older than the populations in those studies. Next, in 2 studies, ${ }^{7,25}$ the length of exposure to oral antidiabetes drugs was not the same for all participants, which makes the interpretation of cumulative incidence difficult. In the third, ${ }^{24}$ individuals who discontinued oral antidiabetes drugs in the 18-month period before insulin initiation were excluded. This exclusion criterion may be a potential source of bias because people who discontinued oral antidiabetes therapy during the first 18 months may have been switched to insulin therapy. Therefore, in these studies, factors reported as being associated with insulin initiation should be interpreted with caution.

\section{Limitations}

Our study provides "real-world" insight from a populationbased cohort of elderly people taking oral diabetes medications; however, several limitations should be considered when interpreting the results. First, studies have reported that thiazolidinediones may delay the onset of insulin initiation. ${ }^{26} \mathrm{Be}$ cause we excluded patients initially taking a thiazolidinedione, we were not able to confirm this finding in our population. Second, analysis of medications was based on pharmacy refills; however, refilling may not represent the actual use of drugs. Third, we were not able to assess whether insulin initiation by new users of oral antidiabetes drugs was because of a higher body mass index, severity of diabetes or failure to achieve glycemic control because these clinical data are not captured in the Régie de l'assurance maladie du Québec database. Lastly, patient preferences, perception of health or beliefs about their disease and its treatment were not available in the administrative databases. Thus, the associations that we reported were limited to the examination of an incomplete set of variables.

This study was based on information gathered between 1998 and 2004. Although during that period, insulin initiation was mainly considered to represent secondary failure of oral antidiabetes drug therapy, insulin is now recommended as the initial treatment for patients with type 2 diabetes and marked hyperglycemia., ${ }^{2,4}$ It is therefore unclear whether the factors associated with insulin initiation indicate secondary failure of oral antidiabetes drug therapy or simply better management of type 2 diabetes. Indeed, recent improvements in the organization of care have made it easier and safer to care for older patients with diabetes.

The main disadvantage of insulin therapy is hypoglycemia. Reported benefits for patients with type 2 diabetes include improved well-being and possibly quality of life,,$^{27,28}$ as well as improved cognitive function, ${ }^{29}$ partly because of improved glycemic control. However, others have found lower treatment satisfaction in patients taking insulin. ${ }^{30}$ Although the advantages of better metabolic control in patients with type 2 diabetes have been advocated for a long time, in particular for patients aged 40-55 years, ${ }^{31,32}$ this has recently been challenged by a study showing that intensive glucose therapy may be beneficial only in patients aged 65 or fewer years. ${ }^{33}$ The clinical decision to initiate insulin requires that the benefits should outweigh the risks. ${ }^{2}$

\section{Conclusion}

There is a need for better understanding of the role of insulin in elderly patients who start oral antidiabetes therapy. Further investigation is needed to explore the relation among glycemic control, insulin initiation and health outcomes, notably in elderly patients with type 2 diabetes.

This article has been peer reviewed.

Competing interests: None declared.

Contributors: Norma Pérez contributed substantially to conception and design of the study and to the analysis and interpretation of data. Jocelyne Moisan contributed substantially to conception and design of the study and the interpretation of the data. Caroline Sirois contributed substantially to the analysis and interpretation of data. Paul Poirier substantially contributed to the interpretation of data. Jean-Pierre Grégoire substantially contributed to the conception and design of the study and the analysis and interpretation of the data. Jean-Pierre Grégoire drafted the article, which was critically revised by all of the other authors. All of the authors approved the version submitted for publication.

Acknowledgements: Norma Pérez received a graduate student scholarship from the GEOIDE Network. Caroline Sirois is the recipient of a graduate student scholarship from the Fonds de la recherche en santé du Québec. Paul Poirier is a clinical-research scholar from the Fonds de la recherche en santé du Québec.

The results in this article were previously presented in part at the $23 \mathrm{rd}$ International Conference on Pharmacoepidemiology and Therapeutic Risk Management, 2007 Aug. 19-22, Québec City, Que.

Funding: No external funding was received for this research.

\section{REFERENCES}

1. Turner RC, Cull CA, Frighi V, et al. Glycemic control with diet, sulfonylurea, metformin, or insulin in patients with type 2 diabetes mellitus: progressive requirement for multiple therapies (UKPDS 49). UK Prospective Diabetes Study (UKPDS) Group. JAMA 1999;281:2005-12.

2. Canadian Diabetes Association. Canadian Diabetes Association 2003 Clinical Practice Guidelines for the Prevention and Management of Diabetes in Canada. Can J Diabetes 2003;27(Suppl 2):S1-152.

3. Nathan DM, Buse JB, Davidson MB, et al. Management of hyperglycemia in type 2 diabetes: A consensus algorithm for the initiation and adjustment of therapy. A consensus statement from the American Diabetes Association and the European Association for the Study of Diabetes. Diabetes Care 2006;29:1963-72.

4. American Diabetes Association. Standards of medical care in diabetes 2008. Diabetes Care 2008;31(Suppl 1):S12-54.

5. Matthews DR, Cull CA, Stratton IM, et al. UKPDS 26: sulphonylurea failure in non-insulin-dependent diabetic patients over six years. UK Prospective Diabetes Study (UKPDS) Group. Diabet Med 1998;15:297-303.

6. UK Prospective Diabetes Study (UKPDS) Group. Intensive blood-glucose control with sulphonylureas or insulin compared with conventional treatment and risk of complications in patients with type 2 diabetes (UKPDS 33). Lancet 1998;352:837-53.

7. Donnan PT, Steinke DT, Newton RW, et al. Changes in treatment after the start of oral hypoglycaemic therapy in type 2 diabetes: a population-based study. Diabet Med 2002;19:606-10.

8. Polonsky KS, Sturis J, Bell GI. Seminars in Medicine of the Beth Israel Hospital, Boston. Non-insulin-dependent diabetes mellitus — a genetically programmed failure of the beta cell to compensate for insulin resistance. N Engl J Med 1996; 334:777-83.

9. Groop LC, Pelkonen R, Koskimies S, et al. Secondary failure to treatment with oral antidiabetic agents in non-insulin-dependent diabetes. Diabetes Care 1986;9: 129-33.

10. Groop L, Schalin C, Franssila-Kallunki A, et al. Characteristics of non-insulin-dependent diabetic patients with secondary failure to oral antidiabetic therapy. Am J Med 1989;87:183-90.

11. Johnson SB. Methodological issues in diabetes research. Measuring adherence. $D i$ abetes Care 1992;15:1658-67.

12. Tamblyn R, Lavoie G, Petrella L, et al. The use of prescription claims databases in pharmacoepidemiological research: the accuracy and comprehensiveness of the prescription claims database in Quebec. J Clin Epidemiol 1995;48:999-1009.

13. WHO Collaborating Centre for Drug Statistics Methodology. Anatomical therapeutic chemical (ATC) classification index. Oslo (Norway): the centre; 2000.

14. Schneeweiss S, Seeger J, Maclure M, et al. Performance of comorbidity scores to control for confounding in epidemiologic studies using claims data. Am J Epidemiol 2001;154:854-64. 
15. Cusi K, Consoli A, DeFronzo RA. Metabolic effects of metformin on glucose and lactate metabolism in noninsulin-dependent diabetes mellitus. J Clin Endocrinol Metab 1996;81:4059-67.

16. Pandit MK, Burke J, Gustafson AB, et al. Drug-induced disorders of glucose tolerance. Ann Intern Med 1993;118:529-39.

17. Klein R, Klein BE, Moss SE, et al. The Wisconsin epidemiologic study of diabetic retinopathy. III. Prevalence and risk of diabetic retinopathy when age at diagnosis is 30 or more years. Arch Ophthalmol 1984;102:527-32.

18. Phillips A. Experiences of patients with type 2 diabetes starting insulin therapy. Nurs Stand 2007;21:35-41.

19. Thompson WG. An assault on old friends: thiazide diuretics under siege. Am J Med Sci 1990;300:152-8

20. Barzilay JI, Davis BR, Cutler JA, et al.; ALLHAT Collaborative Research Group. Fasting glucose levels and incident diabetes mellitus in older nondiabetic adults randomized to receive 3 different classes of antihypertensive treatment: a report from the Antihypertensive and Lipid-Lowering Treatment to Prevent Heart Attack Trial (ALLHAT). Arch Intern Med 2006;166:2191-201.

21. O'Byrne S, Feely J. Effects of drugs on glucose tolerance in non-insulin-dependent diabetics (Part I). Drugs 1990;40:6-18.

22. Jandeleit-Dahm KA, Tikellis C, Reid CM, et al. Why blockade of the renin-angiotensin system reduces the incidence of new-onset diabetes. J Hypertens 2005 23:463-73.

23. Gress TW, Nieto FJ, Shahar E, et al.; The Atherosclerosis Risk in Communities Study. Hypertension and antihypertensive therapy as risk factors for type 2 diabetes mellitus. N Engl J Med 2000;342:905-12.

24. Spoelstra JA, Stolk RP, Heerdink ER, et al. Refill compliance in type 2 diabetes mellitus: A predictor of switching to insulin therapy? Pharmacoepidemiol Drug Saf 2003;12:121-7.
25. Spoelstra JA, Stol RP, de Bruyne MC, et al. Factors associated with switching from oral hypoglycaemic agents to insulin therapy. Neth J Med 2002;60:243-8.

26. Wajchenberg BL. Beta-cell failure in diabetes and preservation by clinical treatment. Endocr Rev 2007;28:187-218.

27. Berger W. Insulin therapy in the elderly type 2 diabetic patient. Diabetes Res Clin Pract 1988;4(Suppl 1):24-8.

28. Goddijn PP, Bilo HJ, Feskens EJ, et al. Longitudinal study on glycaemic control and quality of life in patients with type 2 diabetes mellitus referred for intensified control. Diabet Med 1999;16:23-30.

29. Gradman TJ, Laws A, Thompson LW, et al. Verbal learning and/or memory improves with glycemic control in older subjects with non-insulin-dependent diabetes mellitus. J Am Geriatr Soc 1993;41:1305-12.

30. Petterson T, Lee P, Hollis S, et al. Well-being and treatment satisfaction in older people with diabetes. Diabetes Care 1998;21:930-5.

31. Holman RR, Paul SK, Bethel MA, et al. 10-year follow-up of intensive glucose control in type 2 diabetes. $N$ Engl J Med 2008;359:1577-89.

32. The ADVANCE Collaborative Group. Intensive blood glucose control and vascular outcomes in patients with type 2 diabetes. N Engl J Med 2008;358:2560-72.

33. The Action to Control Cardiovascular Risk in Diabetes Study Group. Effects of intensive glucose lowering in type 2 diabetes. N Engl J Med 2008;358:2545-59.

Correspondence to: Dr. Jean-Pierre Grégoire, URESP, Centre hospitalier affilié universitaire de Québec, 1050, ch. Sainte-Foy, Québec QC G1S 4L8; fax 418 682-7962;

jean-pierre.gregoire@pha.ulaval.ca

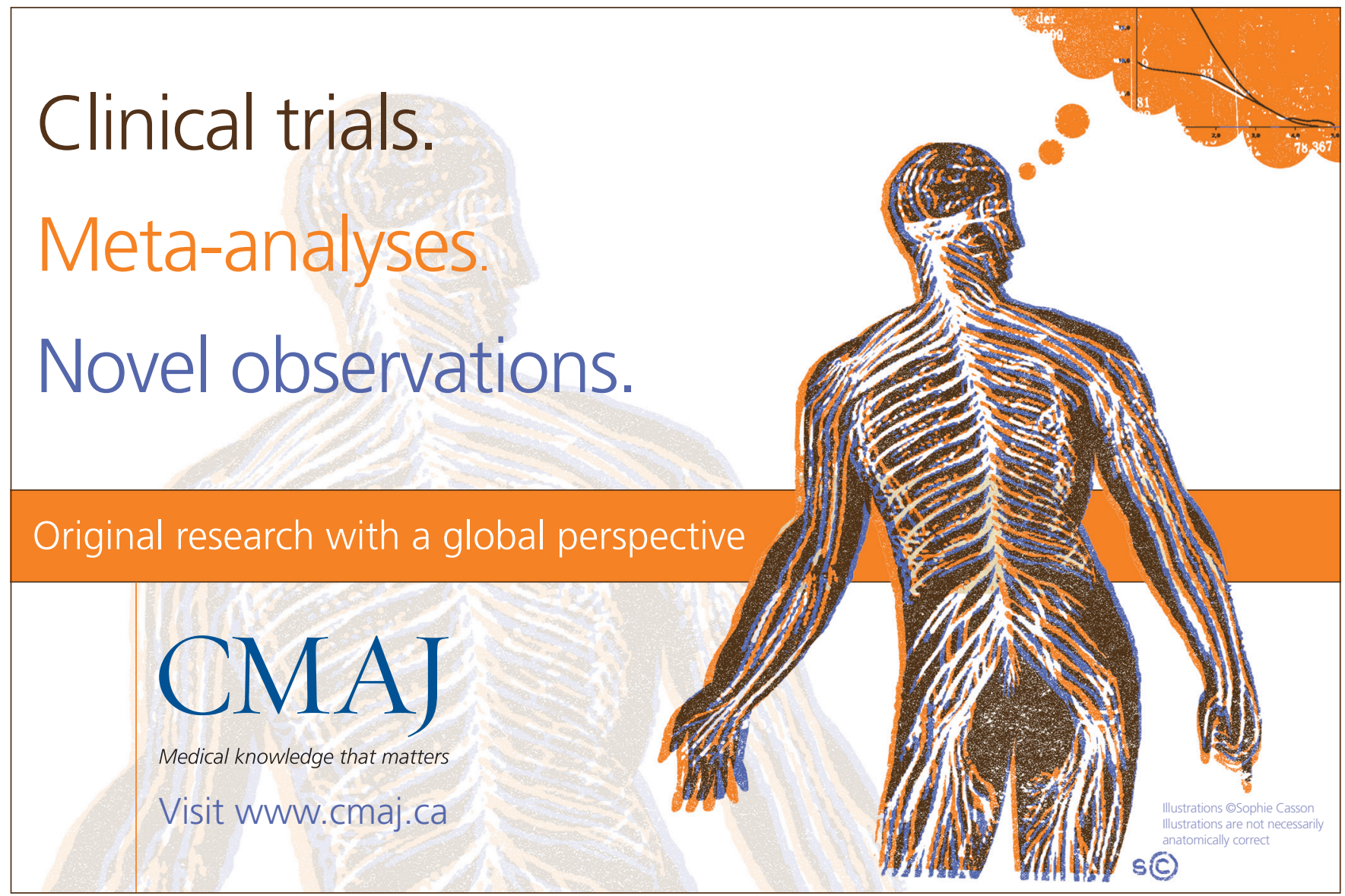

